\title{
Os determinantes políticos no federalismo brasileiro após a Constituição Federal de 1988 e suas implicações na primeira metade dos anos de 1990
}

\author{
The political determinants in Brazilian federalism after the Federal Constitution of 1988 \\ and its implications in the first half of the 1990s
}

\author{
Fábio Luciano Oliveira Costa \\ Doutorando em Educação, \\ Universidade de São Paulo - USP \\ e-mail: fabiolucianocosta@usp.br
}

Recebido: 03/08/2012

Aceito: 22/05/2013
RESUmo Este artigo tem como objetivo principal investigar algumas das características desenvolvidas pelo federalismo no Brasil, após a promulgação da Constituição Federal (CF) de 1988, particularmente nos seus aspectos políticos e as implicações desse processo para os entes federados, principalmente na primeira metade dos anos de 1990. Apesar da abordagem crítica, que procura investigar os conflitos e as contradições inerentes ao processo social, privilegiou-se a análise governamental, com menor destaque para a luta dos movimentos sociais. Além da introdução, que apresenta os elementos centrais do texto, o mesmo conta com mais três partes. Na primeira, analisaram-se algumas das características políticas no federalismo brasileiro com o processo de redemocratização que culminou com o fim do regime militar e, posteriormente, com a promulgação da CF/1988, a qual determinou, mas ainda não conseguiu efetivar, um federalismo cooperativo entre os níveis de governo. Para a segunda, discutiu-se o papel dos entes federados com as novas determinações constitucionais, além, entre outras, das relações entre os três Poderes (Executivo, Legislativo e Judiciário), o sistema partidário e o eleitoral. Dessa forma, evidenciou-se a preponderante presença do Executivo federal nas matérias legislativas de interesse federativo no Congresso Nacional, bem como sua influência nas decisões políticas referentes às transferências legais para os governos subnacionais. Por fim, as considerações finais retomam determinadas questões que foram colocadas ao longo do texto, ressaltando alguns dos principais resultados do trabalho.

PalaVras-Chave Federalismo; Constituição Federal de 1988; Entes Federados.

ABSTRACT This article aims at investigating some of the features developed by federalism in Brazil, after the enactment of the Federal Constitution (FC) 1988, particularly in its political aspects and implications of this case to federal entities, especially in the first half of the year 1990. Despite the critical approach that investigates the conflicts and contradictions inherent in the social process, we focused on the analysis of government, with less emphasis on the struggle of social movements. In the 
introduction, which presents the central elements of the text, it has three parts. At first, we analyzed some of the features in Brazilian federalism policies with the democratization process that culminated with the end of military rule, and later with the enactment of CF/1988, which determined, but has yet to commit, a federalism cooperative relationship between levels of government. For the second, discussed the role of federal agencies with the new constitutional determinations, and, among others, relations between the three powers (executive, legislative and judicial), the party system and elections. Thus, there was a predominant presence of the federal executive in federal legislative matters of interest in Congress, as well as their influence on political decisions concerning legal transfers to SNGs. Finally, concluding remarks take up certain issues that were raised throughout the text, highlighting some of the main results of the work.

KEYwORDS Federalism; Federal Constitution of 1988; Federal Entities.

\section{Introdução}

Este artigo tem como objetivo principal investigar algumas das características desenvolvidas pelo federalismo no Brasil, após a promulgação da Constituição Federal (CF) de 1988, particularmente nos seus aspectos políticos.

Para viabilizar a problemática central, buscou-se compreender como têm sido estruturados os papéis dos entes federados, bem como as relações entre eles com o processo de redemocratização - que levou, entre outros, à promulgação da nova Constituição - , e o período associado à primeira metade dos anos de 1990.

Apesar da abordagem crítica, que procura investigar os conflitos e as contradições inerentes ao processo social, privilegiou-se a análise governamental, com menor destaque para a luta dos movimentos sociais.

Além desta introdução, o texto conta com mais três partes. Na primeira, analisaram-se algumas das características políticas no federalismo brasileiro com o processo de redemocratização que culminou com o fim do regime militar e, posteriormente, com a promulgação da $\mathrm{CF} / 1988$, a qual determinou, mas ainda não conseguiu efetivar, um federalismo cooperativo entre os níveis de governo.

Para a segunda, discutiu-se o papel dos entes federados com as novas determinações constitucionais, além, entre outras, das relações entre os três Poderes (Executivo, Legislativo e Judiciário), o sistema partidário e o eleitoral.

Por fim, as considerações finais retomam determinadas questões que foram colocadas ao longo do texto, ressaltando alguns dos principais resultados do trabalho.
Mesmo com a mobilização de distintos setores da sociedade brasileira no processo de transição democrática e do papel desempenhado pelos governadores na construção de uma opinião pública que lutou pelo voto direto para a presidência da República, inclusive permitindo a indicação de um deles pelo Congresso Nacional, em 1985, por meio de eleição indireta, a sustentação de Gomes (2006) é a de que a democratização foi feita de cima para baixo.

O período foi marcado pelo forte controle dos dirigentes militares e a possibilidade de sua intervenção, caso fossem solicitados, para a manutenção da ordem vigente, camuflada dessa vez com o discurso democrático elaborado pelas elites urbanas e rurais, apoiado por setores variados da classe média e mesmo pobre.

Caracterizado como Nova República, o governo da transição democrática foi comandado pelo antigo líder do partido do regime militar, José Sarney (1985-1990), que assumiu o cargo da presidência da República, depois da morte de Tancredo Neves (PMDB), desencadeando o fim do modelo de intervenção estatal nacional-desenvolvimentista, iniciado com Getúlio Vargas na década de 1930, bem como para que fosse possível inserir as reformas neoliberais tardias na década de 1990 (Arturi, 2001).

\section{Nova República, Nova Constituição e um Federalismo de Bases Cooperativas?}

O período de democratização no país foi ampliado durante o governo civil de José Sarney, com, entre 
outros: 1) o fim da perseguição aos partidos de oposição; 2) a expansão do sufrágio aos analfabetos em 1985; 3) a aprovação da nova Constituição em 1988 ; 4) a reorganização dos movimentos sindicais (mediante a formação de três grandes centrais de sindicatos nacionais) antes controlados pelo Estado; e 5) a realização das eleições diretas para presidente da República em 1989, que não aconteciam desde 1961 (Tavares e Fiori, 1993).

Se os personagens políticos na redemocratização tiveram como preocupação predominante tentar não cometer os principais erros do regime militar na administração pública do país, como no caso da recessão econômica, das políticas públicas de caráter minimalista, do excesso de burocratização nos estados e municípios e da restrição da atuação governamental pela fragmentação das empresas estatais, a perspectiva de construção de um novo Estado não levou em consideração os tradicionais problemas históricos da sociedade brasileira.

Como exemplos, citam-se a ausência da Reforma Agrária e de políticas eficientes que pudessem vir a reduzir a má distribuição da riqueza interna e proporcionar, para o conjunto da população, melhorias significativas na qualidade de vida.

De forma geral, o governo Sarney frustrou as expectativas advindas com a redemocratização, sobretudo pelo seu caráter populista e a pouca preocupação com o desenvolvimento de políticas públicas, as suspeitas de corrupção e o descontrole inflacionário com o insucesso dos planos econômicos ${ }^{1}$.

Quando o governo federal começou a elevar as negociações das questões nacionais com os governos subnacionais, fortaleceu-se o processo democrático e o federalismo no país, mas a descentralização acabou por não levar à diminuição significativa das desigualdades regionais, ainda que tenha havido redução relacionada ao poder financeiro da União.

Assim, a reformulação da divisão de poder político e fiscal em federações se torna ineficiente onde permaneçam ainda fortes desequilíbrios, o que desencadeará, contudo, pressões e disputas entre os entes federados (Souza, 2001b).

Em fevereiro de 1987, foi instalada a Assembléia Nacional Constituinte (ANC), formada por 24 subcomissões, as quais tiveram como função iniciar os trâmites da nova Constituição. Os trabalhos promovidos mobilizaram variados segmentos da sociedade civil e diferentemente de outras constituintes, os anteprojetos foram discutidos, votados pelas subcomissões e posteriormente

\footnotetext{
1 Os Planos Cruzados I e II, implantados em 1986; o Plano Bresser, de 1987; além do Plano Verão, de 1989
}

rediscutidos e reunidos em comissões temáticas, em número de oito, não coordenadas e com atuações independentes entre si.

Aprovados nas comissões, os textos foram direcionados para a Comissão de Sistematização, para em seguida serem apreciados - com a inserção ou não de emendas -, obtendo sua aprovação, com duas rodadas de votações nominais, no Plenário Nacional Constituinte (Araújo, 2005).

Pela alta diversidade dos constituintes, somada à abrangência da transição política, Souza (2001a) distinguiu duas opções no que se refere ao processo decisório. Na primeira, onde grupos com identidades ideológicas semelhantes efetivaram acordos que confrontaram conservadores versus progressistas; para a segunda, onde grupos adversários fizeram acordos que geraram consenso em algumas questões, e em outras, prolongando a falta desse para ocasiões posteriores.

Como prevaleceu, em geral, a falta de consenso no processo político decisório para a aprovação da nova Constituição, coube ao deputado federal, Ulysses Guimarães, presidente da ANC - que teve como relator interno, o senador Fernando Henrique Cardoso (FHC) -, a mediação da instabilidade política para a formação de acordos comuns.

O novo texto constitucional, promulgado em 5 de outubro de 1988, determinou a repartição de poderes, competências e concessões legislativas aos entes federados (com os municípios alçados agora a essa condição), ressaltando suas autonomias e ofícios privativos comuns ou concorrentes, dentro das limitações estabelecidas.

No art. $1^{\circ}$ da $\mathrm{CF} / 1988$, determinou-se para a República Federativa do Brasil, composta pela "união indissolúvel dos Estados e Municípios e do Distrito Federal", os desígnios da mútua cooperação entre os entes federados, conforme os arts. $1^{\circ}, 18,23$ e $60, \S$ $4^{\circ}$, inciso I (Brasil, 1988).

A descentralização de poderes passou legalmente a permitir a criação e maior participação de novos atores sociais aptos a tomarem decisões políticas, inspirados pelo modelo institucional cooperativo, o qual deveria ser realizado pelo sistema de colaboração negociado que não excluiu - nem poderia excluir em um sistema federativo -, a competição ${ }^{2}$ entre os entes federados.

Essa poderia ocorrer, também, pela resolução de embates advindos de problemas associados à

\footnotetext{
Bobbio (2000) destaca a competição associada à democracia, como um sistema político que leva à falta de consenso, o qual se apresenta apenas no que diz respeito às regras da competição e concorrência. Nesse sentido, não raro, tem sido possível encontrar estreita associação entre federalismo e democracia.
} 
má interpretação das leis e da certificação de seu cumprimento, pela prestação de serviços públicos ou garantia da representação política, subsidiados pelo Estado Democrático de Direito.

Apesar do avanço em destacar o regime de colaboração federativo, a CF/1988 não esclareceu como esse processo, para a boa governabilidade da nação, poderia ser consumado, pois no seu art. 23, lei complementar (Brasil, 1988) ${ }^{3}$ deveria fixar regras para a cooperação entre a União, os estados, o Distrito Federal e os municípios, o que até hoje não foi feito pelos parlamentares. Nesse ponto, os avanços legais não se transformaram em avanços reais que pudessem realmente determinar a colaboração entre os entes federados.

Mas as limitações ao modelo de federalismo cooperativo no Brasil vão muito além da omissão constitucional, remetendo à problemática institucional, que acaba por explicar, em parte, as desigualdades financeiras, políticas e administrativas, legitimando as capacidades diferenciadas dos governos subnacionais em promover as políticas públicas.

O que se tem vai mais ao encontro da competição do que da cooperação (horizontal e vertical) entre os entes federados, com poucos veículos institucionais que possam intermediar os interesses e negociar os conflitos. Assim, Souza (2001a: 23) justifica que:

A trajetória do federalismo brasileiro confirma a visão de que o federalismo como mecanismo de divisão territorial de poder é mais uma forma de acomodar conflitos regionais do que de promover harmonia. Também confirma o argumento de que o federalismo é mais uma ideologia baseado em valores e interesses do que um compromisso baseado em arranjos legais e territoriais ou em propósitos democráticos. As relações federativas tendem a ser mais baseadas em interesses conflitantes, que, por sua vez, refletem outros conflitos políticos existentes na sociedade.

O art. 18 da CF/1988 (Brasil, 1988) abordou a Organização Político-Administrativa da República Federativa do Brasil, definindo a União, os estados, o Distrito Federal e os municípios como entes autônomos, de acordo com os termos constitucionais.

A autonomia política, jurídica e administrativa é associada às responsabilidades dos entes federados, com a possibilidade de punições para o não cumprimento de tais atribuições, inclusive por meio da intervenção da União nos estados, no Distrito Federal

\footnotetext{
${ }^{3}$ Com a Emenda Constitucional (EC) no 53/2006 (Brasil, 2006), esse artigo, em seu parágrafo único, alterou a redação para "leis complementares", na tentativa de facilitar a regulamentação no regime de colaboração entre os entes federados.
}

ou nos municípios, ou dos estados nos seus respectivos municípios, caso haja ruptura do pacto federativo que venha a desrespeitar as regras constitucionais (arts. 34, 35 e 36 da CF/1988) (Brasil, 1988).

Para os entes federados, a definição das competências, uma das prerrogativas que definem o maior ou menor caráter de restrição ao poder das maiorias, na CF/1988, em seus arts. 21 e 22 especificaram as competências privativas da União, no art. 23, as competências comuns para os entes federados e no art. 24, as competências concorrentes (Brasil, 1988).

As demais competências residuais ou remanescentes para os estados, Distrito Federal e municípios, nos arts. 25, 29, 30 e 31 (Brasil, 1988) destacaram, em especial, as competências tributárias de cada nível de governo.

\section{Papel dos Entes Federados Após a Promulgação da Constituição Federal de 1988}

A República Federativa do Brasil conta com o sistema de governo presidencialista, em que o presidente é o chefe de governo e de Estado, eleito pelo voto popular, o qual dispõe de poderes legislativos constitucionais, sobretudo no que diz respeito aos assuntos orçamentários, além de nomear e dirigir a composição do governo.

O sistema eleitoral é multipartidário, o qual pode ser majoritário para a escolha dos mandatos fixos do presidente, governador, senador ${ }^{4}$ e prefeito, ou proporcional com lista aberta, por meio do voto dos eleitores (direcionado a um candidato ou partido) para deputados (federais, estaduais ou distritais) e vereadores, em mandatos de quatro anos.

Aspectos importantes do sistema político brasileiro foram alterados com a CF/1988, determinando novas regras para seu funcionamento, vistas, por exemplo: 1) na ampliação dos poderes legislativos do Executivo, como na apresentação ao Congresso Nacional de propostas de emendas constitucionais, muitas delas aprovadas; 2) edição de Medidas Provisórias (MPs), substituindo os decretos-lei; 3) leis com requerimento de delegação do Congresso; 4) pedidos de urgência; e 5) poder para restringir emendas parlamentares (Amorim Neto, Cortez e Pessoa, 2011).

\footnotetext{
${ }^{4} \mathrm{O}$ art. 46 da CF/1988, em seus $\$ \S 1^{\circ}, 2^{\circ}$ e $3^{\circ}$ (Brasil, 1988) determinam que os senadores dos estados e do Distrito Federal sejam eleitos pelo voto majoritário, em número de três representantes, com dois suplentes cada, pelo mandato de oito anos, cuja representação dos governos subnacionais será renovada a cada quatro anos, de forma alternada, por um e dois terços.
} 
No entanto, as bases estruturais desse sistema político continuaram muito próximas daquele criado em 1946. No sistema de representação proporcional de lista aberta, o quociente eleitoral atua como mecanismo de barreira, mesmo com o voto facultativo (pois é permitido votar na legenda), que tem sido amenizado por meio das coalizões partidárias.

Além disso, as lideranças partidárias tiveram elevados os recursos legislativos para comandar suas bancadas e manifestar interesses regionais ou locais, de acordo com o Regimento Interno da Câmara dos Deputados (Limongi e Figueiredo, 1998; Melo e Anastasia, 2005).

Junto com as normas de representação para formar maiorias estáveis, em virtude do multipartidarismo, as coalizões no "presidencialismo de coalizão" (Abranches, 2003: 52) também ocorreram pelas diversidades sociais dos interesses em jogo e da heterogeneidade de fatores políticos, econômicos e sócio-culturais, pela probabilidade de permitir a sobrevivência de partidos que recebem menos votos, bem como pela possibilidade de instituir escolhas para além das legendas partidárias.

Contraditoriamente, a diminuição do número de partidos com representação parlamentar e elevação na desproporcionalidade da relação entre votos e número de cadeiras, tende a criar constantes mudanças e questionamentos sobre a legitimidade no processo decisório.

As particularidades inauguradas com a $\mathrm{CF} / 1988$ no sistema político brasileiro determinaram novas competências para os entes federados, inclusive elevando os municípios a essa categoria, fato particular entre as federações.

No que tange às competências exclusivas dos entes federados, coube à União - mesmo com a aprovação de medidas que fortaleceram os governos subnacionais -, conforme ressaltado no arts. $21 \mathrm{e}$ 22 da CF/1988 (Brasil, 1988), o maior número de atribuições ${ }^{5}$, incluindo todas as políticas estratégicas, ainda que realizadas pelos governos subnacionais.

Assim, abordaram-se desde aspectos relacionados com a política externa, garantia da defesa nacional e política monetária, até as diversificadas políticas, entre outras, que tratam da energia elétrica, desenvolvimento urbano, transporte (aéreo, terrestre e marítimo) e trânsito, comunicação, recursos hídricos, recursos minerais, emprego, segurança e educação.

\footnotetext{
Somadas, essas atribuições chegaram a 54 itens, 25 para o art. 21 e 29 para o art. 22. As áreas concorrentes, encontradas no art. 24, nas quais a União, os estados, o Distrito Federal e os municípios podem legislar, somaram 16 itens. O art. 23 da CF/1988 (Brasil, 1988), que colocou as competências comuns entre os entes federados, apresentou 12 itens.
}

A tradição histórica do fortalecimento da União, para Arretche (2010: 590), pode ser explicada tanto pela ideia de nação, mediante o "sentimento de pertencimento a uma comunidade nacional única", quanto na falta de crédito relacionada à má governabilidade das elites políticas locais. Esse processo tenderia a limitar a prática da discordância e as desigualdades territoriais entre as jurisdições dos entes federados, pela sobreposição do governo federal sobre os governos subnacionais, restringindo, por exemplo, a capacidade desses em implantar políticas próprias.

Papel importante é exercido pelo Judiciário na figura do Supremo Tribunal Federal (STF), dotado com o poder de resolver conflitos políticos, inviabilizando total ou parcialmente estatutos legais federais. Como as propostas do Executivo tem tido poucas rejeições quando votadas no Congresso Nacional, depois de 1988, esse poder atribuído ao STF conquistou destacada relevância.

Parte-se aqui do pressuposto defendido por Arretche (2009), de que, após a promulgação da CF/1988, além do fortalecimento dos poderes jurisdicionais da União, houve a limitação dos vetos institucionais aos governos subnacionais, principalmente porque as relações normativas entre o governo federal e os estaduais acabaram por beneficiar as instâncias do Legislativo, definindo uma sequência, e não ruptura, entre as regras na legislação constitucional de 1988 e as dos anos de 1990.

Para corroborar esses argumentos, a autora, no mesmo trabalho indicado, analisou 59 processos legislativos de interesse federativo, como Propostas de Emenda à Constituição (PECs), Projetos de Lei Complementar (PLPs), Projetos de Lei (PLs) e MPs.

Neles foram tratados temas como tributação, gastos e encargos, de 1989 a $2006^{6}$, compreendendo os governos dos presidentes Sarney (no seu final), de Fernando Collor de Mello (Collor/1990-1992), Itamar Franco (1992-1994), FHC (1995-2002) e o primeiro governo de Luiz Inácio Lula da Silva (Lula/2003-2006), com suas tramitações e votações realizadas no Congresso Nacional, onde inclusive, em alguns, determinando perdas para todos os governos subnacionais.

As altas taxas de aprovação das matérias legislativas iniciadas pelo Executivo, de 1988 a 2006, no caso, de MPs, foram divididas em dois grupos por Limongi (2006: 21). O primeiro mostra o índice de sucesso

\footnotetext{
${ }^{6}$ A extensão do período de análise, nesta parte do trabalho, para além da primeira metade dos anos de 1990, permite-nos melhor compreender a forte presença do Executivo federal no Congresso Nacional.
} 
como "proporção do que é aprovado sobre o total enviado por este poder" à Câmara dos Deputados; o segundo representa os índices de dominância, que correspondem à "divisão das leis cuja proposição se deve ao Executivo pelo total de leis aprovadas no período".

O sucesso médio foi de $70,7 \%$, e a dominância de $85,6 \%$ nas votações consideradas por esse autor, ou seja, a tendência evidenciou que o Legislativo aprovou boa parte do que foi submetido pelo Executivo.

Os poderes da União foram expressos também na forma como disciplinou e limitou a arrecadação dos impostos de competência exclusiva dos governos subnacionais, mesmo com as perdas de recursos tributários para outros entes federados, na escolha de representantes políticos, pela maneira como foram gastos esses recursos e sobre as políticas instauradas de acordo com suas atribuições, demonstrando ainda o forte caráter centralizador.

Contudo, não se afirmam apenas continuidades com relação aos poderes da União sobre os dos governos subnacionais, mas também rupturas ao longo da primeira metade dos anos de 1990. Como exemplo, cita-se a maior independência (descentralização) de estados e municípios sobre seus gastos, bem como na transferência da execução de políticas, que em muitos casos levou apenas a repasses de atribuições (desconcentração), mas não à autoridade para legislá-las e, posteriormente executá-las conforme suas próprias definições.

Se a descentralização passou a ser a grande bandeira defendida com a CF/1988, no governo Collor, ela foi parcialmente recolhida, mas isso não impediu que a totalidade das matérias constitucionais de interesse federativo, votadas na Câmara dos Deputados, em seu mandato, fosse aprovada em votação legislativa (Arretche, 2009).

Algumas das medidas passaram a restringir a autoridade de todos os governos subnacionais sobre suas políticas e sobre seus gastos, como a Lei de Concessões (Lei n ${ }^{\circ}$ 8.987/1995) (Brasil, 1995a) e a Lei Camata [Lei Complementar (LC) $n^{\circ}$ 82/1995] (Brasil, 1995b) - posteriormente legisladas no governo FHC -, ainda que, como coloca Mainwaring (1993), o presidente Collor tivesse fraco vínculo com seu partido e uma tendência antipartido ${ }^{7}$.

\footnotetext{
Essa tendência também foi utilizada pelo autor para caracterizar o governo Sarney na presidência da República, mas não durante o período de sua carreira política na União Democrática Nacional (UDN), na Aliança Renovadora Nacional (ARENA) e no Partido Democrático Social (PDS).
}

Sucesso quase que também obtido por Itamar Franco ${ }^{8}$, caso não tivesse ocorrido rejeição de apenas uma de suas matérias de interesse federativo votadas na Câmara Baixa. Instrumentos legislativos importantes foram aprovados nesse período, entre eles, a Lei de Licitações (Lei no 8.666/1993) (Brasil, 1993) e o Fundo Social de Emergência ${ }^{9}$ (FSE), que desvinculou $20 \%$ das receitas da União, ao afetar, sobretudo os estados mais pobres e municípios de pequeno porte.

Dessa forma, caso os governos de estados e municípios - pertencentes ou não às regiões mais pobres ou mais prejudicadas do país com as novas medidas -, tenham sido contrários a essas aprovações, não conseguiram mobilizar suas bancadas na Câmara Baixa para vetar as matérias legislativas, demonstrando maior fidelidade dos parlamentares ao líder partidário e ao governo federal, do que ao partido do governador.

O argumento apresentado por Mainwaring (1993) e Palermo (2000) é o de que a formação de um sistema multipartidário fragmentado, indisciplinado, com sobrerrepresentação dos estados menos populosos e, conforme Abrucio (1994), forte influência dos governadores sobre suas bancadas parlamentares, possibilitada pelas variadas características do sistema eleitoral, deveriam gerar governos federais que não poderiam conseguir maioria nas Câmaras Legislativas.

Isso levaria ao desencadeamento de conflitos entre o Legislativo e o Executivo, pouca mobilidade política e baixos incentivos para a cooperação. Apesar de suas afirmações referendarem a ausência de meios institucionais para lidar com essas situações, as coalizões partidárias (com poucas dissensões) e as negociações promulgadas pelas elites políticas acabaram por reverter essa imobilidade.

O que prevaleceu foi o poder de agenda e apoio da maioria, independente da popularidade do presidente da República, em que os presidentes depois dos anos de 1990, tiveram a quase totalidade de suas matérias de interesse federativo aprovadas no Congresso Nacional, pela disciplina dos parlamentares frente às orientações dos líderes partidários.

\footnotetext{
${ }^{8}$ Itamar Franco assumiu a presidência da República depois do impeachment de Collor em 1992, fruto das denúncias de corrupção que levaram às mobilizações populares e à ação do Congresso Nacional para resolver a crise política.

${ }^{9}$ EC de Revisão n ${ }^{\circ} 1 / 1994$ (Brasil, 1994), substituída pela EC n ${ }^{\circ}$ 10/1996 (Brasil, 1996a), que originou o Fundo de Estabilização Fiscal (FEF), e pela EC n ${ }^{\circ} 27 / 2000$ (Brasil, 2000), que criou Desvinculação das Receitas da União (DRU) e alterou os dispositivos dos arts. 71 e 72 do Ato das Disposições Constitucionais Transitórias (ADCT) da CF/1988 (Brasil, 1988). Desde sua criação, a DRU tem sido prorrogada e, no dia 20 de dezembro de 2011, foi estendida até 2015.
} 
No interior das Câmaras Legislativas, "instituições igualitárias e majoritárias" (Limongi e Figueiredo, 1998: 91), os votos dos parlamentares no Congresso Nacional recebem o mesmo peso. Para dar andamento aos seus trabalhados, os representantes eleitos pela população distribuem de maneira heterogênea os recursos e direitos parlamentares, no caso brasileiro, sob os postulados partidários.

As lideranças partidárias representam suas bancadas, influenciam seus procedimentos legislativos, determinam a alocação dos parlamentares e a constituição partidária, bem como encaminham para o plenário os trabalhos legislativos, que se torna o principal centro para a tomada de decisões políticas, evitando a possível dispersão do poder possibilitada pelas normas constitucionais.

Nas duas Câmaras, as regras da proporcionalidade partidária comandam a distribuição interna do poder, como no caso da Mesa Diretora que o centraliza no interior do Legislativo, cujos cargos são ocupados mediante o tamanho da representação de suas bancadas, tendo na presidência um representante do partido majoritário que dispõe de importantes poderes para tentar solucionar os impasses apresentados.

O direito de representação dos líderes partidários, eleitos pelas suas bancadas, é legitimado pelos regimentos internos das Câmaras, estabelecendo também o funcionamento do Colégio de Líderes. No caso da Câmara dos Deputados, o colegiado tem função primordial na ordenação dos trabalhos em pauta, estabelecida pela coordenação do presidente da Mesa e dos líderes partidários (Limongi e Figueiredo, 1998), o que, por sua vez, torna a possibilidade dos parlamentares, individualmente, pequenas para influenciar os rumos dos trabalhos legislativos.

Essas regras também acabam por fazer com que sobressaiam os poderes legislativos de um Executivo federal "imperial" (Codato, 2005: 84), levando à tendência de cooperação, e não de exclusão, dos congressistas diante da agenda presidencial (Guimarães, 2004).

Para a aprovação de ECs, torna-se necessário promover dois turnos de votação tanto na Câmara dos Deputados quanto no Senado, dentro da mesma legislatura. A maioria parlamentar é relativamente baixa, quando comparada com outros países federativos, ou seja, de $60 \%$ em quatro votações, apresentando-se como o mecanismo que possui maior dificuldade para alterar a legislação brasileira.

Aprovada uma EC, as designações passam a valer para todo o território nacional e não poderão contar com mais nenhuma possibilidade de veto. Assim, se o presidente conseguir formar uma coalizão com estabilidade e maioria nas duas Câmaras, suas chances de aprovar ECs, ou qualquer outra matéria legislativa, será fortalecida, independente se chegam ou não a prejudicar os governos subnacionais. Com a CF/1988, o poder institucional de veto das minorias foi limitado, caso não consigam formar maiorias oposicionistas nas Câmaras Legislativas.

O chefe do Executivo federal, conforme Palermo (2000), no intuito de formar maioria parlamentar, em meio a baixos incentivos institucionais (como o sistema multipartidário e regionalizado, o bicameralismo e o poder de veto dos governadores), reparte os ministérios entre vários partidos e concede benefícios políticos diversos para os integrantes da coalizão partidária que participam do governo, tornando-o mais fraco em seu próprio gabinete.

Muitos dos votos no Congresso Nacional correspondem à retribuição dos benefícios conseguidos pelos parlamentares, caso contrário, as punições podem ocorrer com a possível perda dos privilégios, adquiridos pelas negociações políticas.

O termo cunhado por Abrucio (2005: 48), da formação de um "federalismo estadualista e predatório", de 1982 a 1994, com bases não cooperativas, em conflito ao que foi exposto por Arretche (2009) sobre seu estudo relacionado às matérias de interesse federativo, de 1989 a 2006, remete ao enfraquecimento do poder da União e do presidente da República, atrelados à crise do modelo de financiamento do Estado nacionaldesenvolvimentista, à falta de equilíbrio das contas públicas do país e ao excesso de burocracia no âmbito federal.

Como justificativa para a ampliação do poder dos governos estaduais, o autor também destaca, além da diminuição dos poderes da União, a excessiva presença dos governadores no processo decisório de seus territórios, com poucas opções institucionais e sociais que viessem a controlar ou contestar suas governabilidades, além da fidelidade das bases locais ao Executivo estadual para obter os cargos tanto no Legislativo estadual quanto no federal.

Ainda, somam-se a liderança de determinadas elites regionais no Congresso Nacional ao longo do período de redemocratização, seja ela por meio do partido, ou mesmo pelas coalizões partidárias, bem como a presença de instituições chefiadas pelos governos estaduais, como bancos ou empresas estatais, que ampliaram o sistema de poder financeiro e administrativo das elites regionais (Abrucio, 2005).

Assim, a maior influência dos governadores no Congresso Nacional teria ocorrido pelo fato de que as eleições para senadores e deputados federais estavam vinculadas à do governador, na tentativa de aumentar as chances de vitória eleitoral dos candidatos, 
principalmente para os deputados federais, decretando os vínculos de lealdade entre os grupos políticos regionais que seriam cobrados pelos governadores na legislatura dos parlamentares. Entre as medidas que mostrariam o poder dos governadores, a principal seria o veto a ordenações colocadas pelo governo federal que não fossem com eles negociadas anteriormente.

Segundo Souza (1998), as vias para as negociações entre os estados e a União poderiam se feitas de três maneiras: 1) nomeação de pessoas para os cargos da burocracia federal e diretoria de empresas públicas ${ }^{10}$; 2) facilitação financeira, por meio do direcionamento de maior parcela de recursos da União para os estados; pela liberação de incentivos, subsídios e empréstimos a juros menores por instituições controladas pelo governo federal; ou pelo apoio a empréstimos com instituições internacionais; e 3) renegociação com o governo federal das dívidas estaduais e das dívidas dos bancos estaduais nas mãos dos estados, também por meio das instituições financeiras do governo federal e com as instituições internacionais.

Assim, o "federalismo estadualista e predatório" (Abrucio, 2005: 48) teria favorecido os governos estaduais nas esferas políticas e financeiras, pelo menos até a implantação do Plano Real, em 1994.

No entanto, não gerou acordos solidários entre os governos estaduais em prol da construção coletiva de melhorias nacionais, e sim, atitudes muitas vezes particularistas e individuais, com acordos que viessem a atender interesses restritos para a manutenção do status quo vigente, na luta pela maior aquisição de recursos financeiros provenientes da União (Kugelmas e Sola, 1999).

Ora, pelo que foi apresentado até agora para o papel dos estados, percebe-se claro embate com o que foi exposto primeiramente sobre o papel da União. Depois de um longo e excessivo período de centralização por parte do Executivo federal no regime militar, sem dúvida alguma, a redemocratização teria que necessariamente elevar a participação dos outros entes federados, ou seja, dos estados (Distrito Federal) e municípios, ampliando também a margem de poder dos Legislativos, e mesmo dos Judiciários, ainda muito dependentes dos Executivos.

Isso explicaria, em parte, a ampliação dos poderes dos governadores e a articulação desenvolvida com os Legislativos (estadual e federal), pelo menos durante

\footnotetext{
${ }^{10}$ Mainwaring (1993: 41) definiu o favorecimento político como "oportunidades de patronagem", em que tais recursos "permitem aos políticos distribuir benfeitorias em seus redutos eleitorais", para os membros do seu partido, da coalizão política, ou para os da oposição, o que geralmente é usual em todas as instâncias políticas dos entes federados, não se constituindo também, nesse caso, fenômeno exclusivo para o país.
}

o processo que culminou nas eleições diretas para governadores em 1982, na transição democrática e na Nova República, mas que não coincide com todo o período delimitado, estendido até a inauguração do Plano Real, mediante a análise de Arretche (2009), a qual norteia os rumos deste artigo.

Novamente, as conclusões a que chegou a autora não permitiram afirmar que ocorreu uma perda significativa de poderes da União, sobretudo após a promulgação da $\mathrm{CF} / 1988$, pelo fato de que, com apenas uma única exceção, no governo de Itamar Franco, todas as matérias legislativas de interesse federativo por ela analisadas foram aprovadas.

Fato que ocorreu desde o governo Sarney até o final do primeiro governo Lula, já que o poder de veto dos governos estaduais às iniciativas federais dependeu da política em questão, pois

[...] regras constitucionais, legados de políticas prévias e o ciclo da política estruturam diferentemente as arenas decisórias, condicionando as estratégias e as chances de sucesso dos atores federativos. (Arretche, 2002: 434).

Como mudanças significativas de grande porte não ocorrem de um dia para o outro, a possibilidade de continuidades tende a ser maior do que as rupturas, o que não exclui as últimas. Ao contrário da suposta aliança entre os governadores e suas bancadas para a aprovação, ou reprovação de matérias legislativas, a fidelidade parlamentar esteve relacionada com os líderes partidários, em meio às coalizões que foram formadas para atender à agenda do Executivo, e não a dos governadores, após a promulgação da CF/1988.

Mas é possível afirmar certo grau de razão para as duas interpretações, pois houve sim ampliação dos poderes não só dos governadores, mas também de outras instituições políticas, a exemplo dos poderes dos Legislativos e Judiciários, características do federalismo, principalmente depois da $\mathrm{CF} / 1988$, bem como o fato de que esse fortalecimento não se deu com os executivos estaduais exercendo o controle, por meio das bancadas regionais, sobre a Assembleia Legislativa federal.

$\mathrm{NaCF} / 1988$, os poderes residuais ou remanescentes atribuídos aos estados foram redigidos no art. $25^{11}$, e no seu $\S 1^{\circ}$ (Brasil, 1988), podem os mesmos assumir competências, como de políticas relacionadas à educação, saúde, meio ambiente, energia e outras, desde que não sejam vedadas ou entrem em conflito com as regras constitucionais.

\footnotetext{
${ }^{11}$ Nesse artigo, os estados passaram a ter o direito de escrever suas próprias Constituições, promulgadas no ano de 1989 para todos os governos estaduais brasileiros.
} 
Todavia, convém destacar que no contexto atual, pela fragilidade política, econômica e administrativa de muitos estados e também de boa parte de seus municípios, o desenvolvimento e implementação de políticas públicas eficazes e duradouras, no âmbito local, sem o apoio do governo federal, tornam-se praticamente inviáveis.

O art. 18 da CF/1988, em seu $\S 3^{\circ}$ (Brasil, 1988), tornou possível a ampliação da federação, mediante a criação de novos estados, que depende da aprovação da população, por meio da realização de um plebiscito e da confirmação do Congresso Nacional com a aprovação de LC. Três novos estados foram criados em 1988. Pelo art. 13 do ADCT, o estado do Tocantins, desmembrado do estado de Goiás, e pelo art. 14, os antigos Territórios Federais do Amapá e Roraima.

Com a criação do estado de Rondônia, em 1981, de Mato Grosso do Sul, em 1977, e do Acre, em 1962, a sobrerrepresentação política desses e outros estados menos populosos, com a sub-representação dos mais populosos, foi ampliada no Congresso Nacional, além da atribuição de representação política ao Distrito Federal $^{12}$. Vantagens políticas e econômicas aparecem com a criação de novos estados, principalmente para os territórios mais pobres e com menor população.

Na área política, destacam-se a maior representação, segundo critérios desproporcionais, dos estados menos populosos nas decisões do Legislativo.

Para a econômica, os novos estados passaram a ter competências exclusivas sobre a tributação de determinados impostos, como o Imposto sobre a Circulação de Mercadorias e Serviços (ICMS), o Imposto sobre a Propriedade de Veículos Automotores (IPVA), o Imposto sobre a Transmissão de Bens Imóveis Causa Mortis e Doação (ITCMD), a cota de parte do Fundo de Participação dos Estados e do Distrito Federal (FPE), além de maiores chances de poder negociar politicamente recursos com o governo federal.

Com o processo de criação de novos governos estaduais, também foram ampliados os gastos com a máquina administrativa, perdendo não só os estados mais ricos como também os mais pobres, que foram obrigados a dividir parte das insuficientes transferências legais com os novos entes federados (Soares e Lourenço, 2004).

A desproporcionalidade na representação ocorre, sobretudo porque a legislação eleitoral coloca os estados como distritos e fixa o número máximo de 70 (setenta), e mínimo de 8 (oito) deputados federais para sua representação na Câmara Baixa, bem como

\footnotetext{
${ }^{12}$ As competências exclusivas relativas ao Distrito Federal foram definidas no art. 32 da CF/1988 (Brasil, 1988).
}

o número fixo de três senadores por estado para a representação na Câmara Alta.

Introduzida com o Código Eleitoral de 1932, a maior representação dos estados com economias mais vulneráveis, para contrabalançar à época os maiores poderes dos estados de São Paulo e Minas Gerais, tem resultado na fragilização do princípio democrático de representação política, embora a tentativa de forçar a inclusão de problemas, políticos e econômicos, oriundos das desigualdades regionais na agenda política nacional, tenha por objetivo amenizar essas disparidades e permitir o funcionamento do sistema federativo.

Stepan (1999) mostrou que para o ano de 1991, caso houvesse um sistema de representação igualitário, o estado de Roraima teria elegido um deputado federal, enquanto que o de São Paulo algo próximo a cento e quinze, ao invés de oito para o primeiro e setenta para o segundo. No Senado ${ }^{13}$, os números apresentados relataram que os estados que contavam com $13 \%$ do eleitorado detinham $51 \%$ dos votos, ao passo que os estados com $87 \%$ do eleitorado poderiam ter suas políticas barradas, caso a maioria que representa pouco mais de $10 \%$ do eleitorado assim o quisesse.

A essas características, soma-se o fato de que a legislação eleitoral permite

[...] a celebração de coligações para eleições proporcionais, gerando uma disjunção entre o sistema partidário eleitoral e o sistema partidário parlamentar. (Anastasia e Nunes, 2006: 22).

Tais mecanismos colocam o federalismo brasileiro calcado em instituições políticas instáveis, cujos processos decisórios tendem a restringir severamente a manifestação da vontade da maioria, de acordo com os mecanismos de representação política nas Câmaras (Alta e Baixa), que desembocam no poder de veto dos estados menores.

Ainda, ocorre a possibilidade de imobilização da agenda de reformas políticas dos presidentes, entre outros, quando: 1) o Congresso Nacional e os governadores têm poder de veto; 2) houver poder residual dos estados caso não haja manifestação constitucional; 3) existir uma Constituição com muitos detalhes; 4) da necessidade de supermaiorias para emendar a Constituição, ainda que relativamente baixa quando comparada com outras federações; e 5) em alguns casos, da indisciplina dos parlamentares para com as lideranças partidárias.

\footnotetext{
$\overline{{ }^{13} \text { Os arts. } 52 \text { e } 53 \text { da CF/1988 }}$ determinaram as competências privativas da Câmara dos Deputados e do Senado Federal (Brasil, 1988).
} 
Não só os estados foram beneficiados, diante dos fatores internos, mas também em um contexto no qual a tendência internacional orientava para a descentralização da gestão pública, como também os municípios, elevados à categoria de entes federados - segundo a CF/1988 (art. $1^{\circ}$ ) (Brasil, 1988) -, com autonomia política, financeira, administrativa e personalidade jurídica.

No plano político, fora a propriedade de eleger seus próprios governantes (prefeitos, vice-prefeitos e vereadores), também a capacidade de organização por meio de Lei Orgânica foi delegada aos municípios (art. 29 da CF/1988) (Brasil, 1988).

Os governos municipais, no plano administrativo passaram a poder organizar as responsabilidades locais, entre elas, variadas políticas públicas como: alimentação e abastecimento, crianças e adolescentes, educação, emprego e renda, habitação e urbanismo, meio ambiente, projetos agrícolas, saúde e outros, assim como elaborar os cargos dos serviços municipais e de criar ou extinguir distritos. A autonomia jurídica permitiu legislar sobre assuntos de caráter local, bem como complementares às legislações estaduais ou à legislação federal.

$\mathrm{Na}$ esfera financeira, a autonomia tributária possibilitou-lhes: 1) criar e arrecadar seus próprios tributos; 2) propor, aprovar e exercer a gestão do orçamento municipal, com algumas limitações constitucionais; 3) participar do orçamento da União; e 4) ampliar suas receitas tributárias, em termos absolutos e em relação ao Produto Interno Bruto (PIB).

A promulgação da $\mathrm{CF} / 1988$ deu origem a um processo de fragmentação dos municípios brasileiros, em meio a poucos incentivos para se estabelecer a cooperação com os estados, a exemplo dos embates fiscais e do grande número de novos municípios que foram criados, tendo permanecido em muitos locais um patrimonialismo oligárquico, oposto às intenções de descentralização e democracia. Além disso, o texto constitucional não colocou em pauta os múltiplos problemas sociais oriundos da expansão das grandes metrópoles ${ }^{14}$, na última metade do século XX.

$\mathrm{O}$ "municipalismo autárquico", termo cunhado por Abrucio (2010: 45), foi marcado pela heterogeneidade das políticas públicas nas mais diversas localidades do país, relacionada com a diversidade na capacidade

\footnotetext{
${ }^{14}$ As grandes regiões metropolitanas tiveram que ceder parte de seus recursos orçamentários na divisão intergovernamental com a criação dos novos pequenos municípios, prevalecendo o municipalismo, em contraposição a mecanismos de gestão territorial compartilhados Também foram enfraquecidas institucionalmente pela expansão dos problemas sociais, quando comparadas com o período anterior, do regime militar
}

de administração e financiamento dos municípios, utilização de recursos próprios para o financiamento de políticas públicas mediante a vontade política dos seus governantes, ou pela permanência da complementação de recursos pela União e pelos estados, com vistas a possibilitar o cumprimento da agenda política, econômica e social municipal. Em outro trabalho, esse autor afirma que:

O municipalismo autárquico incentiva, em primeiro lugar, a "prefeiturização", tornando os prefeitos atores por excelência do jogo local e intergovernamental. Cada qual defende seu município como uma unidade legítima e separada das demais, o que é uma miopia em relação aos problemas comuns em termos "micro" e macrorregionais. Ademais, há poucos incentivos para que os municípios consorciem-se, dado que não existe nenhuma figura jurídica de direito público que dê segurança política para os governos locais que buscam criar mecanismos de cooperação. Mesmo assim, em algumas áreas, os consórcios desenvolveram-se mais, como em meio ambiente e na saúde, porém ainda em uma proporção insuficiente para a dinâmica dos problemas intermunicipais. Ao invés de uma visão cooperativa, predomina um jogo em que os municípios concorrem entre si pelo dinheiro público de outros níveis de governo, lutam predatoriamente por investimentos privados e, ainda, muitas vezes repassam custos a outros entes, como é o caso de muitas prefeituras que compram ambulâncias para que seus moradores utilizem os hospitais de outros municípios, sem que seja feita uma cotização para pagar as despesas. Nesse aspecto, a questão da coordenação federativa é chave. (Abrucio, 2005: 50).

Grande parte das políticas assumidas pelos municípios pós-1988 ocorreu de forma desorganizada, com exceção para a área da saúde, que possibilitou melhor cooperação entre os entes federados, mas ainda com muito a desejar. Até o início do Plano Real, em um período no qual os índices inflacionários chegaram a quatro dígitos anuais, tornou-se constante as instabilidades nos repasses de recursos, a corrupção e os desvios de verbas, colocando entraves para que os governos subnacionais pudessem cooperar entre si, de forma a atender às suas políticas públicas.

Alguns dados permitem melhor compreender a expansão dos governos municipais depois do período de redemocratização ${ }^{15}$, em que os estados assumiram

\footnotetext{
${ }^{15}$ Intensa criação de municípios também ocorreu no período de 1946 a 1964, enquanto que no período posterior, do regime militar, praticamente não houve formação de novos municípios, o mesmo ocorrendo no período Vargas.
} 
a função de decidir sobre a criação ou extinção de municípios, atribuição que antes da CF/1988 competia à União.

Entre os anos de 1984 a 1997, surgiram no cenário brasileiro 1.405 municípios, com a maior contribuição absoluta das regiões Sul e Nordeste, o que representou um aumento de $34,3 \%$, pois em 1984 , o número de municípios era de 4.102. Dos 1.405 municípios, 735 $(52,3 \%)$ contavam com menos de 5 mil habitantes, 360 $(25,6 \%)$ com população de 5.001 a 10.000 habitantes, $234(16,7 \%)$ com população entre 10.001 e 20.000 habitantes e, por fim, $76(5,4 \%)$ com população acima de 20.000 habitantes (Gomes e Macdowell, 2000).

Segundo os dados apresentados pelos autores, a esmagadora maioria dos novos municípios criados nesse período foi de pequeno porte. Assim, no ano de 1997, dos 5.507 municípios brasileiros, 25,6\% tinham menos de 5 mil habitantes (a proporção para o ano de 1940 era de 2\%), 50\% menos de 10 mil e $74,8 \%$ menos de 20 mil (a proporção em 1940 era de 54,5\%).

Sobre a questão financeira, no ano de 1996, da receita corrente total disponível para os municípios de até 5 mil habitantes, apenas $8,9 \%$ constituía-se de receita própria, ou seja, arrecadada por eles. A proporção aumentou com o crescimento populacional das cidades no Brasil e nas suas regiões de forma geral, pois para os municípios com população entre 10 mil e 20 mil habitantes, os índices foram de 12,3\% e para os municípios com população acima de 1 milhão de habitantes, $55,9 \%$ de suas receitas foram por eles arrecadadas (Gomes e Macdowell, 2000).

Incapazes de gerar arrecadação própria que pudesse atender suas necessidades, esses pequenos municípios ficaram (e ainda ficam) extremamente dependentes das transferências (legais e negociadas) de recursos tributários, principalmente dos impostos federais (gerados majoritariamente nos municípios de maior porte), em especial, do Fundo de Participação dos Municípios (FPM).

Depois da intensa expansão do número de municípios no país nesse período, a EC n ${ }^{\circ}$ 15/1996 (Brasil, 1996b) devolveu a responsabilidade da criação de municípios para a União, dando nova redação ao art. 18, § $4^{\circ}$, da $\mathrm{CF} / 1988$ (Brasil, 1988), normatizando um pouco mais esse processo, de modo que alterações nas unidades municipais passaram a depender de estudos que comprovem sua viabilidade, da realização de plebiscito de todos os municípios envolvidos na emancipação e constatação de período hábil, estabelecido em lei federal, para a efetivação da emancipação.

As iniciativas dos governos locais, com menor capacidade econômica, fiscal, administrativa e institucional, não foram e não são suficientes para romper com certos entraves da gestão pública e das desigualdades sociais. Transferência de gestão deve acompanhar o repasse de recursos e/ou elevação do poder de arrecadação condizente com as novas funções, bem como assistência técnica necessária, caso contrário, a ineficácia se torna praticamente certa para a realização de qualquer serviço público.

A flexibilidade, sob os parâmetros da tendência internacional, como apontava Thereza Lobo (1990), consultora do Banco Mundial no começo dos anos de 1990, que levaria ao processo de descentralização com maior eficiência e igualdade, tratando de forma diferenciada os governos subnacionais segundo suas particularidades econômicas e financeiras, técnicas e administrativas, políticas e sociais, não foi alcançada.

Alguns dos fatores que contribuíram para essa falta de êxito estiveram associados às desigualdades sociais entre as regiões brasileiras, a exemplo da capacidade de gestão e arrecadação dos municípios de pequeno, médio e grande porte, não permitindo que grande parte dos governos subnacionais pudesse atender de forma equilibrada suas distintas demandas de políticas sociais para expressiva parcela da população nacional.

\section{Considerações Finais}

O governo da Nova República foi comandado pelo antigo líder do partido dos militares, o presidente José Sarney, após a morte de Tancredo Neves. Nesse processo, ampliar a descentralização, que recebeu impulso importante com a CF/1988, foi considerado sinônimo de democracia, no sentido de possibilitar o crescimento da participação popular sobre os processos de tomadas de decisões políticas.

No mandato do presidente Sarney, acrescenta-se também o aumento das dívidas externa e interna, os fortes embates no Congresso Nacional e as muitas trocas na equipe do governo, fato que contribuiu para promover, por meio das instituições públicas, a ineficiência da reforma administrativa e constituição de um processo decisório muito lento.

Mesmo depois da abertura política, evidenciou-se a preponderante presença do Executivo federal nas matérias legislativas de interesse federativo no Congresso Nacional, bem como sua influência nas decisões políticas referentes às transferências legais para os governos subnacionais. $\mathrm{O}$ incipiente regime de colaboração entre os entes federados remete à debilidade institucional, que explica, em parte, as fortes desigualdades no federalismo brasileiro.

Tais mecanismos se tornaram possíveis, também, em virtude da instabilidade no multipartidarismo do país, a qual estruturou um presidencialismo de coalizão partidário, mediado pela influência das 
lideranças partidárias nas negociações políticas, para atender a interesses diversos, públicos e/ou privados.

No presidencialismo brasileiro, o presidente pode governar por MPs, em que conta com um Congresso Nacional e partidos políticos, em muitos casos, relativamente fracos, fragmentados, clientelistas e suscetíveis à corrupção.

O sistema eleitoral beneficia mais os candidatos do que os partidos, com distorções na representação política tanto para o Legislativo federal (Câmara Alta - voto majoritário; Câmara Baixa - voto proporcional com lista aberta), quanto estaduais e municipais (voto proporcional com lista aberta).

A elevação da autonomia dos governos subnacionais, inclusive com o expressivo aumento dos governos municipais no final dos anos de 1980 e primeira metade de 1990, junto com uma maior participação da sociedade civil (organizada ou não) instalaram uma democracia com muitos problemas, em meio a um federalismo marcado muito mais pela competição do que a cooperação entre os entes federados.

\section{Referências}

Abranches, Sérgio Henrique Hudson de. 2003. Presidencialismo de Coalizão: o dilema institucional brasileiro. In: J. A. G. Tavares (org.), O sistema partidário na consolidação da democracia brasileira. Brasília: Instituto Teotônio Vilela, p. 21-73.

Abrucio, Fernando Luiz. 1994. Os Barões da federação. Lua Nova, 33: 165-190. http://dx.doi.org/10.1590/ S0102-64451994000200012

Abrucio, Fernando Luiz. 2005. A coordenação federativa no Brasil: a experiência do período FHC e os desafios do governo Lula. Revista de Sociologia e Política, 24: 41-67. http://dx.doi.org/10.1590/ S0104-44782005000100005

Abrucio, Fernando Luiz. 2010. Federalismo e políticas públicas: o impacto das relações intergovernamentais no Brasil. In: E. Levy e P. Medeiros (orgs.), Construindo uma Nova Gestão Pública. Natal: SEARHH/RN, p. 23-51.

Amorim Neto, Octavio; Cortez, Bruno Freitas e Pessoa, Samuel de Abreu. 2011. Redesenhando o mapa eleitoral do Brasil: uma proposta de reforma política. Opinião Publica, 17(1): 45-75. http://dx.doi. org/10.1590/S0104-62762011000100002

Anastasia, Fátima e Nunes, Felipe. 2006. A reforma de representação. In: L. Avritzer e F. Anastasia (orgs.), Reforma política no Brasil. Belo Horizonte: Editora UFMG, p. 17-34.

Araújo, Gilda Cardoso. 2005. Município, federação e educação: história das instituições e das idéias políticas no Brasil. Tese (Curso de Pós-Graduação em Educação), Universidade de São Paulo.
Arretche, Marta Teresa da Silva. 2002. Federalismo e relações intergovernamentais no Brasil: a reforma de programas sociais. Dados, 45(3): 431-458. http:// dx.doi.org/10.1590/S0011-52582002000300004

Arretche, Marta Teresa da Silva. 2009. Continuidades e descontinuidades da federação brasileira: de como 1988 facilitou 1995. Dados, 52(2): 377-423. http://dx.doi. org/10.1590/S0011-52582009000200004

Arretche, Marta Teresa da Silva. 2010. Federalismo e igualdade territorial: uma contradição em termos? Dados, 53(3): 587-620. http://dx.doi.org/10.1590/ S0011-52582010000300003

Arturi, Carlos Schmidt. 2001. O debate teórico sobre mudança de regime político: o caso brasileiro. Revista de Sociologia e Política, 17: 11-31. http://dx.doi. org/10.1590/S0104-44782001000200003

Bobbio, Norberto. 2000. O futuro da democracia. São Paulo: Paz e Terra.

Brasil. Congresso Nacional. 1988. Constituição da República Federativa do Brasil de 1988. Disponível em: <http://www.planalto.gov.br/ccivil_03/ constituicao/constituicao.htm>. Acesso em: 13 jun. 2008.

Brasil. Congresso Nacional. 1993. Lei no 8.666, de 21 de junho de 1993. Regulamenta o art. 37, inciso XXI, da Constituição Federal, institui normas para licitações e contratos da Administração Pública e dá outras providências. Diário Oficial da República Federativa do Brasil, Brasília, DF, 22 jun. Disponível em: <http:// www.planalto.gov.br/ccivil_03/leis/18666cons.htm>. Acesso em: 13 jun. 2008.

Brasil. Congresso Nacional. 1994. Emenda Constitucional de Revisão $\mathrm{n}^{\circ} 1$, de 01 de março de 1994. Acrescenta os arts. 71, 72 e 73 ao Ato das Disposições Constitucionais Transitórias. Diário Oficial da República Federativa do Brasil, Brasília, DF, 02 mar. Disponível em: <http://www.planalto. gov.br/ccivil_03/constituicao/emendas/ECR/ecr1. htm>. Acesso em: 13 jun. 2008.

Brasil. Congresso Nacional. 1995a. Lei no 8.987, de 13 de fevereiro de 1995. Dispõe sobre o regime de concessão e permissão da prestação de serviços públicos previstos no art. 175 da Constituição Federal, e dá outras providências. Diário Oficial da República Federativa do Brasil, Brasília, DF, 14 fev. Disponível em: <http://www.planalto.gov.br/ccivil_03/leis/ 18987cons.htm>. Acesso em: 13 jun. 2008.

Brasil. Congresso Nacional. 1995b. Lei Complementar $\mathrm{n}^{\text {o }}$ 82, de 27 de março de 1995. Disciplina os limites das despesas com o funcionalismo público, na forma do art. 169 da Constituição Federal. (Lei Camata). Diário Oficial da República Federativa do Brasil, Brasília, DF, 28 mar. Disponível em: <http://www. planalto.gov.br/ccivil_03/leis/lcp/Lcp82.htm>. Acesso em: 13 jun. 2008. 
Brasil. Congresso Nacional. 1996a. Emenda Constitucional $n^{\circ} 10$, de 4 de março de 1996. Altera os arts. 71 e 72 do Ato das Disposições Constitucionais Transitórias, introduzidos pela Emenda Constitucional de Revisão n ${ }^{\circ}$ 1, de 1994. Diário Oficial da República Federativa do Brasil, Brasília, DF, 05 mar. Disponível em: <http://www. planalto.gov.br/ccivil_03/constituicao/Emendas/Emc/ emc10.htm>. Acesso em: 13 jun. 2008.

Brasil. Congresso Nacional. 1996b. Emenda Constitucional $\mathrm{n}^{\circ} 15$, de 12 de dezembro de 1996. Dá nova redação ao $\S 4^{\circ}$ do art. 18 da Constituição Federal. Diário Oficial da República Federativa do Brasil, Brasília, DF, 13 dez. Disponível em: $<$ http://www.planalto.gov.br/ccivil_03/constituicao/ Emendas/Emc/emc15.htm>. Acesso em: 13 jun. 2008.

Brasil. Congresso Nacional. 2000. Emenda Constitucional $\mathrm{n}^{\circ} 27$, de 21 de março de 2000. Acrescenta o art. 76 ao ato das Disposições Constitucionais Transitórias, instituindo a desvinculação de arrecadação de impostos e contribuições sociais da União. Diário Oficial da República Federativa do Brasil, Brasília, DF, 22 mar. Disponível em: <http://www.planalto. gov.br/ccivil_03/constituicao/Emendas/Emc/emc27. htm>. Acesso em: 13 jun. 2008.

Brasil. Congresso Nacional. 2006. Emenda Constitucional $\mathrm{n}^{\circ}$ 53, de 19 de dezembro de 2006. Dá nova redação aos arts. $7^{\circ}, 23,30,206,208,211$ e 212 da Constituição Federal e ao art. 60 do Ato das Disposições Constitucionais Transitórias. Diário Oficial da República Federativa do Brasil, Brasília, DF, 20 dez. Disponível em: <http://www.planalto. gov.br/ccivil_03/constituicao/Emendas/Emc/emc53. htm>. Acesso em: 13 jun. 2008.

Codato, Adriano Nervo. 2005. Uma história política da transição brasileira: da ditadura militar à democracia. Revista de Sociologia Política, 25: 83-106. http:// dx.doi.org/10.1590/S0104-44782005000200008

Gomes, Fábio Guedes. 2006. Conflito social e welfare state: Estado e desenvolvimento social no Brasil. Revista de Administração Pública, 40(2): 201-236. http://dx.doi. org/10.1590/S0034-76122006000200003

Gomes, Gustavo Maia e MacDowell, Maria Cristina. 2000. Descentralização política, federalismo e criação de Municípios: o que é mau para o econômico nem sempre é bom para o Brasil. Instituto de Pesquisa Econômica Aplicada - IPEA, 706: 01-27. Disponível em: <www.ipea.gov.br/pub/td/td_2000/td_706.pdf>. Acesso em: 27 ago. 2011.

Guimarães, Juarez. 2004. A crise do paradigma neoliberal e o enigma de 2002. São Paulo em Perspectiva, 15(4): 136-144. http://dx.doi. org/10.1590/S0102-88392001000400015

Kugelmas, Eduardo e Sola, Lourdes. 1999. Recentralização/Descentralização: dinâmica do regime federativo no Brasil dos anos 90. Tempo Social, 11(2): 63-81. http://dx.doi.org/10.1590/ S0103-20701999000200005
Limongi, Fernando. 2006. A democracia no Brasil: presidencialismo, coalização partidária e processo decisório. Novos Estudos - CEBRAP, 76: 17-41. http:// dx.doi.org/10.1590/S0101-33002006000300002

Limongi, Fernando e Figueiredo, Argelina. 1998. Bases institucionais do presidencialismo de coalizão. Lua Nova, 44: 81-215. http://dx.doi.org/10.1590/ S0102-64451998000200005

Lobo, Thereza. 1990. Descentralização: conceitos, princípios, prática governamental. Cadernos de Pesquisa, 74: 05-10. Disponível em: <http://educa. fcc.org.br/scielo.php?script=sci_arttext\&pid=S010 $015741990000300001 \& \operatorname{lng}=$ pt\&nrm=iso $>$. Acesso em: 02. Out. 2011.

Mainwaring, Scott.1993. Democracia presidencialista multipartidária: o caso do Brasil. Lua Nova, (28-29):21-74. Disponível em: <http://dx.doi. org/10.1590/S0102-64451993000100003>. Acesso em: 13 maio 2011.

Melo, Carlos Ranulfo e Anastasia, Fátima. 2005. A reforma da previdência em dois tempos. Dados, 48(2): 301-332. http://dx.doi.org/10.1590/ S0011-52582005000200003

Palermo, Vicente. 2000. Como se governa o Brasil? O debate sobre instituições políticas e gestão de governo. Dados, 43(3): 521-557. http://dx.doi. org/10.1590/S0011-52582000000300004

Soares, Márcia Miranda e Lourenço, Luiz Cláudio. 2004. A representação dos estados na federação brasileira. Revista Brasileira de Ciências Sociais, 19(56): 113-127. http://dx.doi.org/10.1590/ S0102-69092004000300008

Souza, Celina. 1998. Federalismo e intermediação de interesses regionais nas políticas públicas brasileiras. São Paulo, Seminário Internacional sobre Reestruturação e Reforma do Estado: Brasil e América Latina no Processo de Globalização. Disponível em: <info.worldbank.org/etools/docs/ library/232245/Souza.pdf>. Acesso em: 15 nov. 2011.

Souza, Celina. 2001a. Federalismo e gasto social no Brasil: tensões e tendências Lua Nova, 52: 05-28. http:// dx.doi.org/10.1590/S0102-64452001000100002

Souza, Celina. 2001b. Federalismo e descentralização na Constituição de 1988: processo decisório, conflitos e alianças. Dados, 44(3): 513-560. http://dx.doi. org/10.1590/S0011-52582001000300003

Stepan, Alfred. 1999. Para uma nova análise comparativa do federalismo e da democracia: federações que restringem o poder do Demos. Dados, 42(2): 197-251. http://dx.doi.org/10.1590/ S0011-52581999000200001

Tavares, Maria da Conceição e Fiori, José Luis. 1993. (Des)ajuste global e modernização conservadora. São Paulo: Paz e Terra. 